\title{
1. Creating business value through human-centric AI
}

\section{Margherita Pagani and Renaud Champion}

\section{INTRODUCTION}

Artificial Intelligence (AI) systems are having a great impact on a broad range of business and management subjects ranging from Finance, Marketing, Strategy, to Innovation and Entrepreneurship and covering a multitude of different industries. AI will improve products and processes and make decisions better informed (Davenport 2018).

To become human-centric, AI systems need to integrate new capabilities dealing with human values. A human-centric AI system is thus an AI system that possesses an ethical dimension in addition to its technical functions. In this chapter:

1. We first lay the foundations, opening the black box of AI and identifying human-centric AI;

2. Based on a study on 867 AI systems applied to business processes, we identify the implications for business capabilities. In this respect, we build on the "three-dimensional concurrent engineering" framework which adds value chain engineering to augment the traditional two-dimensional concurrent engineering of products and processes.

3. We highlight the unique value proposition of human-centric AI and identify four main human-machine collaborative modes (see Figure 1.1). 


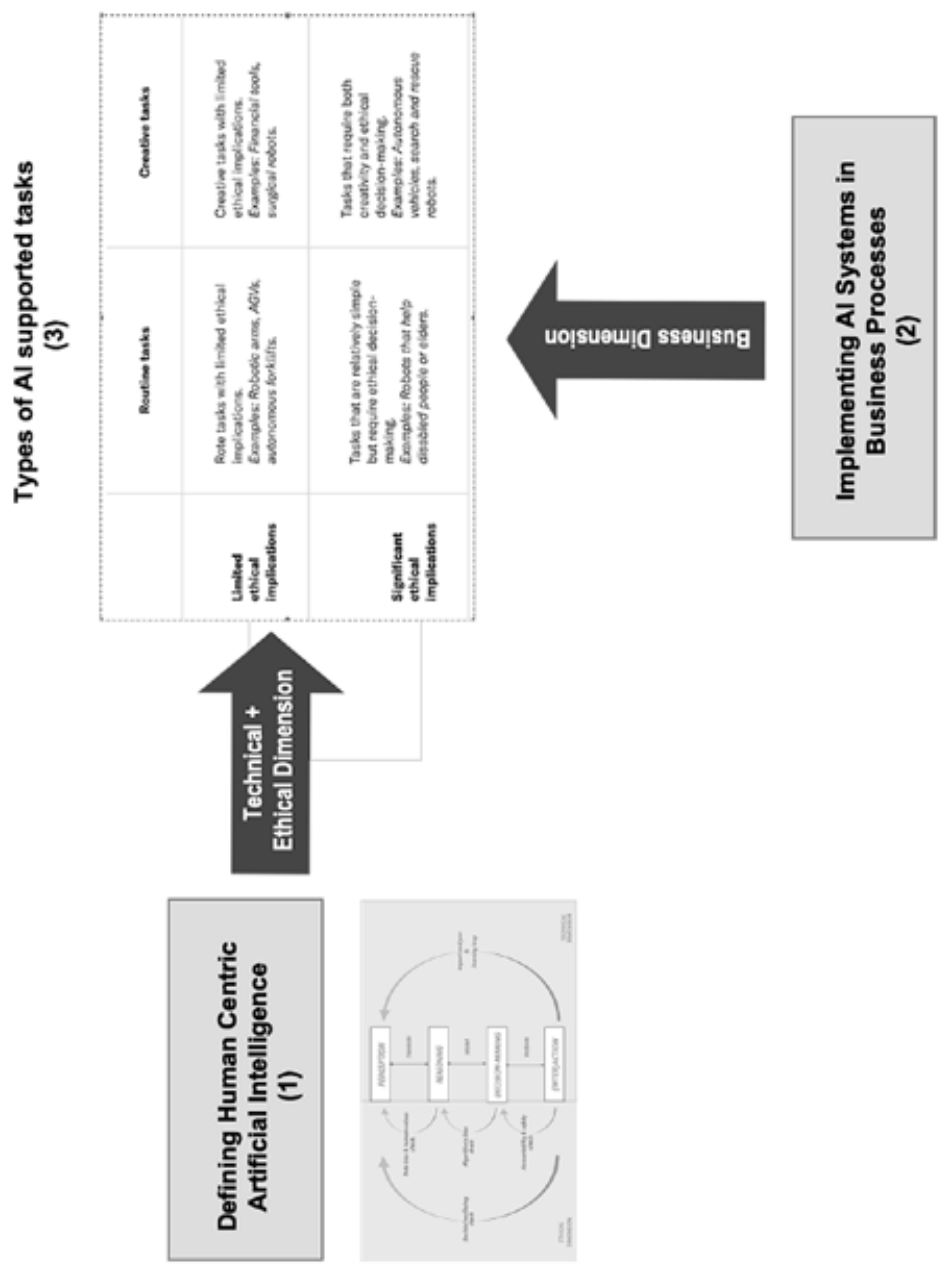

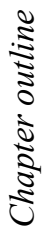

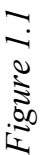




\section{HUMAN-CENTRIC AI SYSTEMS, WHEN ETHICS AUGMENT TECHNOLOGY}

\subsection{From the Original Definition...}

AI systems are rational objects (either software or hardware) designed by humans. They are capable of choosing the best action to take to achieve a specific goal, given certain constraints and available resources. The autonomous vehicle for example is an AI system whose goal is to transport passengers from point $\mathrm{A}$ to point $\mathrm{B}$, avoiding obstacles and obeying traffic rules. To do so, it relies on the data its sensors acquire in real time from the environment (Box 1.1). Similarly, the goal of a shopping recommendation algorithm is to present to a customer a list of preferred articles to buy, based on the understanding of his/her personal tastes, the evolving fashion context, and the e-commerce platforms' offer (Box 1.2). To achieve rationality, the AI system relies on a set of technical capabilities encoded or built in as technical components (McCarthy et al. 2006). The sequence Perception, Reasoning, Decision-making, and (Inter)action is sometimes augmented with a Learning feature. Altogether they are defined as the AI system's life cycle (Figure 1.2).

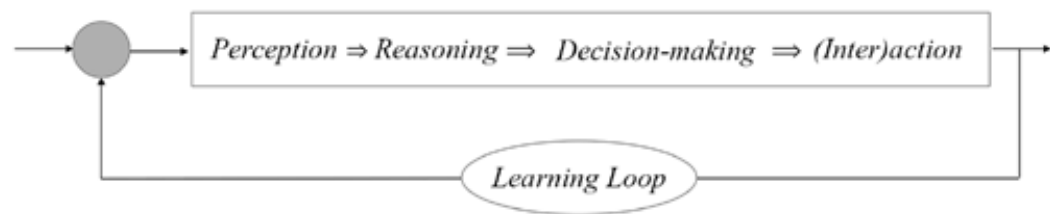

Figure 1.2 AI system's life cycle

- Perception: the AI system perceives the environment (physical or digital) in which it is immersed through sensors. During the process, several sets of heterogeneous data of varying quality are acquired.

- Reasoning: once the data has been collected, the system interprets it to build knowledge. It transforms the raw data into a clear understanding of its environment. It can then reason on what is perceived or process the information derived from the data set.

- Decision-making: based on its knowledge, the AI system defines what is the best action to achieve its goal. It can proceed by making logical deductions or using learning techniques. 
- (Inter)action: the system finally performs the actions decided through actuators (which are devices causing other devices to operate). The interactions can occur between the AI system and its environment, another machine, a human, or an object.

\section{BOX 1.1 CASE 1: THE AUTONOMOUS VEHICLE}

An autonomous vehicle uses cameras, lasers, odometers, or GPS to get data sets about the road but also about the other vehicles, the people around, the infrastructure, its location, etc....-Perception.

The sensors generate a rich set of heterogeneous data that digitally represents the physically complex environment in which the vehicle will operate (a road with traffic, pedestrians, signs, and traffic lights). It will then compare the data coming from its different sensors to precisely identify and classify the surrounding objects (a car moving, a person on a bike, a traffic light going red...). This generates a representation of the physical environment, with its dynamic and static characteristics. With such a representation, the vehicle "knows" in real time what is happening around it - Reasoning.

Consequently, the decision-making algorithm will decide in real time what actions to take (stop, make a left/right turn, slow down, accelerate...) based on the events happening in the environment (a traffic light turning red, a pedestrian suddenly crossing the street, a left turn approaching, a car slowing on an empty highway...), to transport the passengers safely from point A to point $\mathrm{B}$ - Decision-making.

Finally, the action can be mechanical (turn the steering wheel to make a left/right turn, press the brake pedal...) or digital (identification signals sent to the infrastructure, communication with the passengers...). Interactions can occur between the vehicle and the infrastructure, the passengers, or other vehicles - (Inter)action. 


\section{BOX 1.2 CASE 2: THE RECOMMENDATION ALGORITHM}

The shopping recommendation algorithm can use chatbots and online surveys to get information directly from the customer. But it can also connect to social networks (Facebook, Twitter, Instagram...) and identify web-surfing habits to acquire various data (pictures, tweets, contacts profiles, or websites visited) - Perception.

From the data collected, the recommendation system can derive an exhaustive model of the customer's preferences. This model can then be dynamically updated when new information is captured (new "like" on Instagram or Facebook, new tweet with an opinion) - Reasoning.

Based on the preferences model for a customer, the recommendation algorithm can identify on e-commerce platforms which are the best articles to select according to the customer's tastes and the current fashion trends - Decision-making.

Finally, the action can be digital (the display on a website of all the selected articles) or physical (the automatic delivery of the top five articles selected). Interactions can also occur between the algorithm and the customer (a chatbot, an automatic emailing system) or another machine (the automatic order of the articles on a partner e-commerce platform) - (Inter)action.

Some AI systems are able to adapt their behavior over time by learning from their actions. After taking an action at the end of one life cycle, the system evaluates the new state of the environment (through Perception). It can assess how successful the action was compared to the desired goal and then adapt its reasoning rules and its decision-making algorithm according to this feedback. This Learning mechanism can happen in collaboration with humans (supervised learning) or not (unsupervised learning). In the case of the shopping recommendation algorithm, the customer chooses among the articles received the ones he/she prefers and sends back the rest. The system learns from this human feedback and refines its recommendations accordingly for the next order. This learning-by-doing feature integrated into the AI system's life cycle is represented as a feedback loop, a typical tool used in control theory ${ }^{1}$ (Ashby, 1956).

\subsection{To Human-centric AI}

The exponential diffusion of AI systems in our economies and our life is raising many ethical concerns, not only among the scientists and the policymakers but also in public opinion. For instance, some people fear that intensive automation will generate massive unemployment worldwide, thus leading 
to dramatic societal damages. Others consider that the deployment of social robots to take care of our elderly is a threat to social links, or that excessive use of surveillance technologies could lead to societies of abusive control. These ethical issues are so fundamental that they need to be fully integrated into the design, use and deployment of AI systems. To do so, human wellbeing and the common good must be put at the center. AI systems need to be human-centric, with the ultimate goal of improving human welfare and freedom. We believe this can be achieved by adding an ethical dimension to any AI system.

Since its origins, an AI system is first and foremost an engineered object relying on technical components, but to become human-centric it needs to integrate new capabilities dealing with human values.

A human-centric AI system is thus an AI system that possesses an ethical dimension in addition to its technical functions. From a pragmatic point of view, this ethical dimension is guaranteed through the implementation of a series of ethical check procedures throughout the AI system's life cycle (Figure 1.3). Their purpose is to make sure that the perceiving, reasoning, deciding and actuating functions (described above) are operating in a trustworthy, ethical and human-centric way.

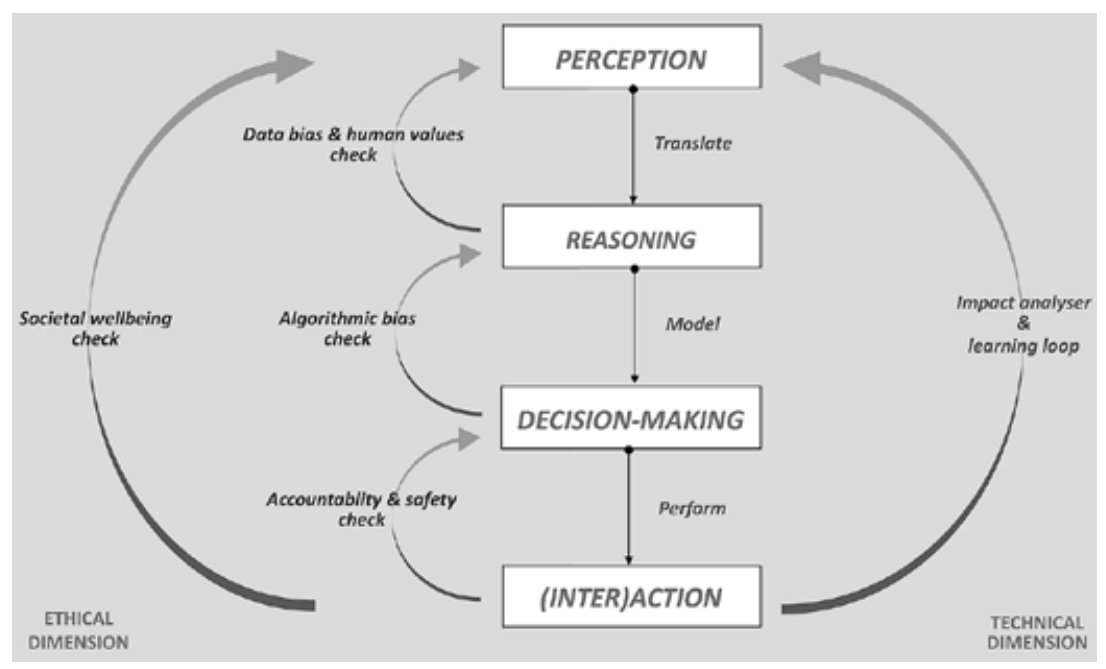

Figure 1.3 Human-centric AI system representation 
- Check for data bias and privacy: data privacy and protection need to be guaranteed by the AI system throughout its life cycle. The quality and the representativeness of the data sets are of paramount importance to avoid misleading representations that could end up in biased decision-making. ${ }^{2}$ The integrity of the data also needs to be ensured.

- Check for algorithmic bias: the algorithms used in the decision-making process have to be nondiscriminatory and explainable in a timely manner. Humans are "biased" by nature because of different cultural, religious or educational backgrounds. So, researchers and engineers who develop the algorithms must be trained to avoid encoding any replication of their raw personal "view of the world". The diversity of the people involved in the coding and the testing processes appears as one efficient way to avoid such bias.

- Check for human-centric values: fundamental rights such as the ones defined in the EU Charter (European Commission 2000) must prevail (Dignity, Freedom, Equality, Solidarity, Citizenship and Justice). These values must be the immutable principles that no AI system should break at any time of its life cycle.

- Check for safety: safety and technical robustness are the safeguards that prevent the AI system from being harmful. The AI system must be resilient to attack (primarily against cyberattacks), secure (including backup procedures and fallback plans), accurate in its judgments (especially when collaborating with humans), and reliable.

- Check for accountability: mechanisms proving auditability and traceability need to be integrated so errors can be identified and explained. This could be a difficult task in some applications where the responsibility chain is difficult to assess clearly (for example the autonomous vehicle).

- Check for human oversight: for specific critical and high-risk applications, a human intervention needs to happen at some level of the decision-making process. In some extreme cases, the human operator is ultimately responsible for the decision. Users should be given the knowledge and the tools to comprehend, interact and possibly challenge the AI systems.

- Check for societal wellbeing: a human-centric AI system should address global concerns as the UN Sustainable Development Goals (United Nations SDG 2015) and never jeopardize human wellbeing (Musikanski et al., 2018). It should operate in respect of social relationships (no deterioration of social links), in respect of society at large (careful consideration of the democratic process and diversity), and in a sustainable manner (environmentally friendly and energy-efficient). 
The check procedures are governed by a series of requirements (Figure 1.4) (European Commission 2019).

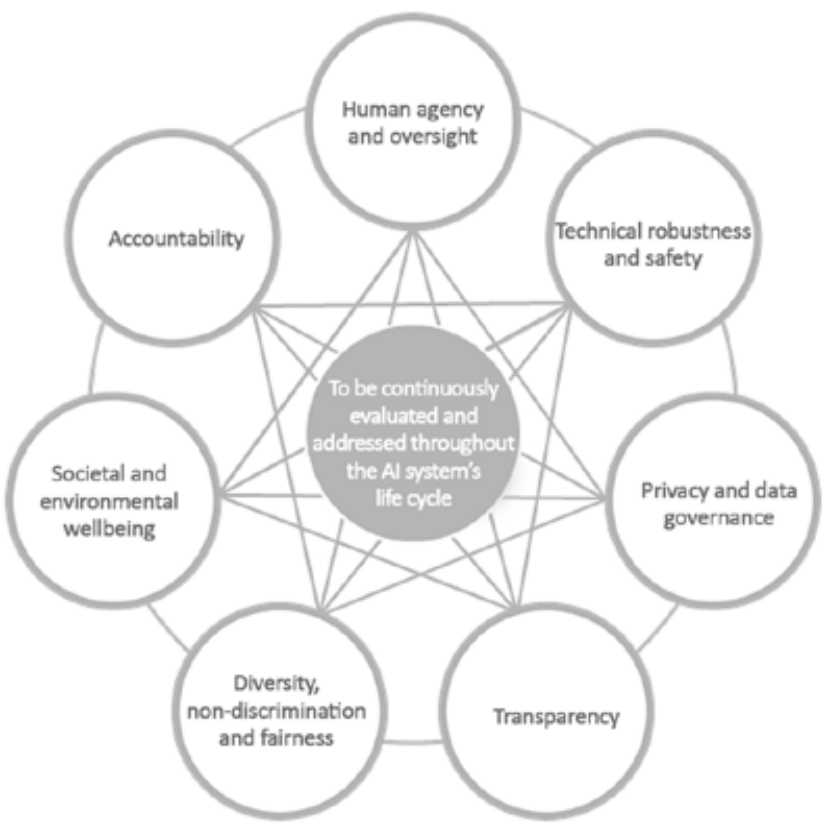

Source: European Commission (2019).

Figure 1.4 Inter-relationship of the requirements for a trustworthy development of $A I$

These check procedures can be of different kinds, and follow technical or nontechnical methodologies. For instance, they can take the form of an ethical variable to be optimized in the algorithms (as in a matchmaking algorithm to avoid gender bias $^{3}$ ), a specific algorithm to manage litigious content (like fake news and deepfakes control procedures), or the alignment with a certification and a set of international standards (like the $\mathrm{CE}^{4}$ marking and the IEEE $\mathrm{P}^{7000}{ }^{\mathrm{TM}}$ series of standards projects ${ }^{5}$ ).

These check procedures, which are part of the Learning Loop in the AI system's life cycle represented in Figure 1.2, can be performed in collaboration between the AI system and a human; they are then called supervised ethical checks. This is the case for the autonomous vehicle confronted with the trolley problem $^{6}$ (Foot 1978). As of today, the AI system is incapable of choosing an action by itself, thus delegating the choice to the passenger. Both the AI 
system and the human operator then collaborate to find the best way to answer this ethical dilemma. On the other hand, if the check procedures are performed by the AI system itself without any outside assistance, then we talk about unsupervised ethical checks. For instance, in the recommendation algorithm, a specific variable can be added in the code aiming at increasing fairness, without compromising the overall performance (Balagué and Rochd 2020).

All human-centric AI systems have a certain level of shared ethical awareness. This level is measured by the system's capacity to address ethical issues autonomously. For this reason, we consider that a human-centric AI system can be characterized as a fully autonomous human-centric AI system if and only if it is autonomous on both its dimensions, that is, technical and ethical. As such, the state-of-the-art autonomous vehicle can't be considered today as fully autonomous because it can't solve the trolley problem alone. This concept of ethical awareness will be further discussed in the last part of this chapter.

\section{IMPLEMENTING AI SYSTEMS IN BUSINESS PROCESSES}

After defining human-centric $\mathrm{AI}$ as linking the ethical requirements to the technical/cognitive dimensions of AI, we look at AI systems now through the lens of business capabilities. With this purpose, we studied 867 real examples of AI systems applied to Business Processes (DeepIndex 2020) in several industries (games, creative industry, home and lifestyle, finance, administrative, industrial, agriculture, transport, government and no profit, education, medicine, science, security, ICT).

We define a business process as a collection of related, structured activities or tasks by people or equipment in which a specific sequence produces a service or product (serves a particular business goal) for a particular customer or customers (Weske 2012; Kirchmer 2017). Each business process can be further split into business functions which are the activities carried out by an enterprise. They can be divided into primary functions (inbound logistics, operations, outbound logistics, marketing and sales, and service) and support functions (research and development, accounting and finance, human resource management, and general management) (Schonberger 1990).

But where exactly do companies in these industries use AI? In what parts of their business are they deploying the technology?

Through the analysis of the 867 real examples and adopting the classification provided by Davenport and Ronanki (2018) integrated by fourth dimension "cognitive interactions", we distinguish four main important business needs (Table 1.1). 

Table 1.1 Classification of AI systems according to business needs and
business functions

\begin{tabular}{|c|c|c|c|}
\hline $\begin{array}{c}\text { Business } \\
\text { needs } \\
\text { supported } \\
\text { by AI }\end{array}$ & $\begin{array}{l}\text { Primary } \\
\text { business } \\
\text { functions }\end{array}$ & $\begin{array}{l}\text { Supportive business } \\
\text { function }\end{array}$ & AI systems \\
\hline $\begin{array}{l}\text { Cognitive } \\
\text { insights }\end{array}$ & $\begin{array}{l}\text { - Marketing } \\
\text { and sales } \\
\text { - Inbound } \\
\text { logistics } \\
\text { - Operations } \\
\text { - Outbound } \\
\text { logistics }\end{array}$ & $\begin{array}{l}\text { - Research and } \\
\text { development } \\
\text { - Accounting and } \\
\text { finance } \\
\text { - Human resource } \\
\text { management } \\
\text { - General management }\end{array}$ & $\begin{array}{l}\text { - Fraud detection: Ability to compare } \\
\text { millions of transactions and distinguish } \\
\text { precisely between legitimate and fraudulent } \\
\text { transactions } \\
\text { - Data security: Identify patterns in how data } \\
\text { in the cloud is accessed, and report anoma- } \\
\text { lies that could predict security breaches } \\
\text { - Marketing: Help to increase the likelihood } \\
\text { of a user clicking by programming targeted } \\
\text { ads and optimizing what product mix to } \\
\text { display } \\
\text { - Recommendations: Ability to determine } \\
\text { what you might like to buy or watch next by } \\
\text { analyzing millions of other users } \\
\text { - Monitoring price changes: Ability for } \\
\text { e-commerce companies to track patterns in } \\
\text { these fluctuations and set prices according } \\
\text { to demand } \\
\text { - Security screening: Eliminate false alarms } \\
\text { and spot things human screeners might miss } \\
\text { and inside the company } \\
\text { in security screenings to ensure safer events } \\
\text { - Online search: Google and its competitors } \\
\text { are constantly improving what the search } \\
\text { engine understands to deliver a better result } \\
\text { in the future } \\
\text { Machine Learning (ML) in financial } \\
\text { risk, (4) Innovating to stay competitive, } \\
\text { and investors to make smarter decisions } \\
\text { in (1) Managing client satisfaction, (2) } \\
\text { Reacting to market trends, (3) Predicting } \\
\text { - }\end{array}$ \\
\hline
\end{tabular}




\begin{tabular}{|c|c|c|c|}
\hline $\begin{array}{c}\text { Business } \\
\text { needs } \\
\text { supported } \\
\text { by AI }\end{array}$ & $\begin{array}{l}\text { Primary } \\
\text { business } \\
\text { functions }\end{array}$ & $\begin{array}{c}\text { Supportive business } \\
\text { function }\end{array}$ & AI systems \\
\hline $\begin{array}{l}\text { Cognitive } \\
\text { insights } \\
\text { (continued) }\end{array}$ & & & $\begin{array}{l}\text { - Monitor wireless network performance and } \\
\text { improve network security, especially in con- } \\
\text { nection with the } 5 \mathrm{G} \text { infrastructure } \\
\text { - Traceability in the supply chain of raw } \\
\text { materials or manufactured products } \\
\text { - Threat detection for security purposes in } \\
\text { sensitive and high-risk sectors (nuclear, } \\
\text { defense, public security) } \\
\text { - Anomaly recognition in manufacturing for } \\
\text { quality inspection (computer vision) }\end{array}$ \\
\hline $\begin{array}{l}\text { Cognitive } \\
\text { engagement } \\
\text { ( } \mathrm{H}-\mathrm{M} \\
\text { interaction) }\end{array}$ & $\begin{array}{l}\text { - Marketing } \\
\text { and sales } \\
\text { - Service }\end{array}$ & $\begin{array}{l}\text { - Human resource } \\
\text { management } \\
\text { - Research and } \\
\text { development }\end{array}$ & $\begin{array}{l}\text { - Language mining: Language processing can } \\
\text { stand in for customer service agents and } \\
\text { more quickly route customers to the required } \\
\text { information } \\
\text { - Personalize customer experience, also in } \\
\text { the physical world through the value-driven } \\
\text { design of smart products (Internet of Things } \\
\text { (IoT)) } \\
\text { - Personalize reskilling and retraining of the } \\
\text { workforce in a lifelong learning process } \\
\text { - Increase sales via chatbot interactions, } \\
\text { personalized nudging based on a fine under- } \\
\text { standing of each customer preferences } \\
\text { - Personalize health monitoring using smart } \\
\text { devices and wearables in health telemetry } \\
\text { - Use of Natural Language Processing (NLP) } \\
\text { in automatic translation to enhance commu- } \\
\text { nication between individuals or economic } \\
\text { agents (intra and inter companies) } \\
\text { - Development of smart interactions between } \\
\text { responsible citizens and their environment } \\
\text { in the smart cities of tomorrow (future of } \\
\text { mobility with autonomous vehicles and } \\
\text { drones, energy monitoring with smart } \\
\text { devices at home, smart consumption with } \\
\text { traceability of ecological signature) } \\
\text { and trustworthy information flows (media, } \\
\text { corporate communication, and Corporate } \\
\text { Social Responsibility (CSR)) }\end{array}$ \\
\hline
\end{tabular}




\begin{tabular}{|c|c|c|c|}
\hline $\begin{array}{c}\text { Business } \\
\text { needs } \\
\text { supported } \\
\text { by AI }\end{array}$ & $\begin{array}{l}\text { Primary } \\
\text { business } \\
\text { functions }\end{array}$ & $\begin{array}{l}\text { Supportive business } \\
\text { function }\end{array}$ & AI systems \\
\hline $\begin{array}{l}\text { Process } \\
\text { automation }\end{array}$ & $\begin{array}{l}\text { - Inbound } \\
\text { logistics } \\
\text { - Operations } \\
\text { - Outbound } \\
\text { logistics }\end{array}$ & $\begin{array}{l}\text { - Research and } \\
\text { development } \\
\text { - Accounting and } \\
\text { finance } \\
\text { - General management }\end{array}$ & $\begin{array}{l}\text { - Medical rehabilitation thanks to robotics and } \\
\text { intelligent prostheses } \\
\text { - Simulation and testing of chemical and } \\
\text { pharmaceutical properties of candidate mol- } \\
\text { ecules in the preclinical trial phase (drugs } \\
\text { and vaccines) } \\
\text { - Robotics-assisted production lines, including } \\
\text { for industrial Small Medium Enterprises } \\
\text { (SMEs) } \\
\text { - Deployment of drones and robotics machin- } \\
\text { ery for crop monitoring, precise farming } \\
\text { in pesticide-reduced agriculture, and cattle } \\
\text { management (milking robots, feeding, and } \\
\text { stable cleaning robots) } \\
\text { - Logistics optimization with warehouses' } \\
\text { robotics management thanks to the deploy- } \\
\text { ment of Autonomous Ground Vehicles } \\
\text { (AGVs) } \\
\text { - Inspection and maintenance with drones and } \\
\text { mobile platforms for utilities and oil and } \\
\text { gas industries, but also civil infrastructures } \\
\text { (bridges, tunnels), planes, or boats } \\
\text { - Dirty, Dull \& Dangerous tasks (DDD tasks) } \\
\text { performed safely by robots (cleaning of } \\
\text { infrastructures, search and rescue operations } \\
\text { ments, construction with large-scale 3D } \\
\text { value and monetize buildings' data } \\
\text { banks or accounting/audit offices } \\
\text { - Review legal contracts/conduct legal case } \\
\text { rearch/write legal papers } \\
\text { - }\end{array}$ \\
\hline
\end{tabular}




\begin{tabular}{|c|c|c|c|}
\hline $\begin{array}{c}\text { Business } \\
\text { needs } \\
\text { supported } \\
\text { by AI }\end{array}$ & $\begin{array}{l}\text { Primary } \\
\text { business } \\
\text { functions }\end{array}$ & $\begin{array}{c}\text { Supportive business } \\
\text { function }\end{array}$ & AI systems \\
\hline $\begin{array}{l}\text { Cognitive } \\
\text { interactions } \\
(\mathrm{M}-\mathrm{M} ; \\
\mathrm{M}-\mathrm{O} ; \mathrm{M}-\mathrm{E})\end{array}$ & $\begin{array}{l}\text { - Operations } \\
\text { - Inbound } \\
\text { logistics } \\
\text { - Outbound } \\
\text { logistics }\end{array}$ & $\begin{array}{l}\text { Research and } \\
\text { development }\end{array}$ & $\begin{array}{l}\text { - Robot-assisted surgeries, AI-augmented } \\
\text { diagnosis for early discovery of health } \\
\text { issues, Virtual Reality (VR) simulation } \\
\text { devices for the training of doctors, and } \\
\text { pre-surgery setup } \\
\text { - Automotive engineering, automotive equip- } \\
\text { ment in the design of subsystems constitut- } \\
\text { ing the autonomous vehicle } \\
\text { - Autonomous professional transporta- } \\
\text { tion (trains, trucks) including public } \\
\text { transportation } \\
\text { - Industrial applications of human-robot col- } \\
\text { laboration involving collaborative robots or } \\
\text { cobots, that physically interact with humans } \\
\text { in a shared workspace to complete tasks } \\
\text { such as collaborative manipulation or object } \\
\text { handovers, generally described under the } \\
\text { acronym Factory of the Future (FoF) } \\
\text { - Master-slave robotics manipulation in } \\
\text { complex environments (nuclear, underwater, } \\
\text { space) } \\
\text { - Haptic control for remote manipulation } \\
\text { by a human operator (surgery, off-site } \\
\text { maintenance) } \\
\text { to robotics arms for improved manipulation } \\
\text { of heterogeneous objects and products (food } \\
\text { industry) }\end{array}$ \\
\hline
\end{tabular}

- Cognitive insights: all tasks that are related to sensing, gathering data from the environment, and building knowledge out of it;

- Cognitive engagement: use natural language processing chatbots, intelligent agents, and machine learning to engage customers and employees;

- Process automation: automation of digital and physical tasks using robotic process automation;

- Cognitive interactions $(M-M, M-O, M-E)$ : synergistic integration of mechanics, electronics, control theory, and computer science within product design and manufacturing, to improve and/or optimize its functionality. 
Looking at the business benefits in greater depth we distinguish seven main effects generated by AI systems functions described above as Perceiving, Reasoning, Decision-making, and (Inter)action (Table 1.2):

- Optimizing internal and external business operations: robotic process automation (RPA) or other technologies allow companies to realize an intelligent automation strategy and optimize internal and external processes automating administrative tasks, thus freeing up workers to be more creative.

- Gaining insights through data analysis: data insights refer to the understanding of a particular business phenomenon by using AI systems to analyze a data set. Using different visualization tools the user is able to better understand and explore data. The clarity of vision from data insights allows an increased model interpretability and better predictions.

- Engaging human-machine interactions: supports powerful new ways to interact with data, such as through conversation, voice, augmented reality, and virtual reality. The user can ask a question in natural language, and the system may be trained through supervised machine learning to understand the intent and analyze the data to generate the right responses. Insights may also be represented visually for the user to explore further. Moreover, AI allows platforms to provide customized recommendations, automated routine purchases, convenience and savings, and reduced complexity (Dawar and Bendle 2018).

- Optimizing automated interactions ( $M-M, M$-Object, M-Environment): the $\mathrm{M} 2 \mathrm{M} / \mathrm{M} 2 \mathrm{O}$ interface allows monitoring, control and management of remote equipment or machines. Remote monitoring, control, and management of devices and machines allow businesses to address maintenance issues and restore functionality. The basis of the M-Environment interaction is the capability of the control system to define primitive geometrical areas to cover all the possible configurations of the objects inside a real industrial cell.

- Enhancing the features, functions, and performance of products: the most important goal for AI systems across industries is improving product and service quality, for example especially in the automotive and utilities industries, healthcare, home appliances thanks to IoT, agro-food business.

- Pursuing new markets: AI systems adoption enables companies to move into new business segments (i.e., micro-segmented, hyper-personalized online shopping platforms), maintain a competitive edge in their industry (for example GPS-driven ride-sharing companies), trigger new opportunities for business monetization (for example, adaptive learning-based EdTech companies) but also transform the physical product into a smart product (embedded AI, robotics). 
- Making smart data out of big data for the entire processing chain: the increasing number of sensors allows a huge amount of data to be captured and has the potential for generating added value along the entire value chain. This is realized by making smart data out of big data for the entire processing chain through AI systems. This depends on boundary conditions such as available data, application type, available sensor modalities, and background information about the lower-level physical processes.

\section{Table $1.2 \quad$ Business benefits of AI systems}

\begin{tabular}{|c|c|}
\hline $\begin{array}{l}\text { Optimizing internal and external } \\
\text { business operations }\end{array}$ & $\begin{array}{l}\text { - Increase competitive advantage and improve efficiency } \\
\text { - Multiply productivity gains by automating processes } \\
\text { - Optimize internal business operations } \\
\text { - Optimize external processes like marketing and sales } \\
\text { - Ensure safe and trustworthy automation }\end{array}$ \\
\hline $\begin{array}{l}\text { Gaining insights through data } \\
\text { analysis }\end{array}$ & $\begin{array}{l}\text { - Improve real time analysis of dataflows } \\
\text { - Make better and more informed decisions } \\
\text { - Capture and apply scarce knowledge needed } \\
\text { - Derive holistic and comprehensive knowledge from unstructured data }\end{array}$ \\
\hline $\begin{array}{l}\text { Engaging human-machine } \\
\text { interactions }\end{array}$ & $\begin{array}{l}\text { - Free up workers to be more creative by automating repetitive and } \\
\text { DDD tasks } \\
\text { - Enhance customer privacy and thereby increase consumer demand } \\
\text { - Advanced automated interactions with customers, partners and } \\
\text { workers }\end{array}$ \\
\hline $\begin{array}{l}\text { Optimizing automated } \\
\text { interactions (M-M, M-Object, } \\
\mathrm{M} \text {-Environment) }\end{array}$ & $\begin{array}{l}\text { - Advanced automated interactions with the business ecosystem } \\
\text { - Define new scheme of interactions between business parties } \\
\text { - Design innovative and more intuitive interfaces for complex } \\
\text { interactions }\end{array}$ \\
\hline $\begin{array}{l}\text { Enhancing the features, functions } \\
\text { and performances of products }\end{array}$ & $\begin{array}{l}\text { - Design smarter machinery, tools and vehicles } \\
\text { - Enhance the features, functions and performance of the products } \\
\text { - Create new products } \\
\text { - Solve identified problems expanding traditional markets (i.e., deep } \\
\text { sea oil and gas exploration with robotic submarines or space explora- } \\
\text { tion with robotic rovers) }\end{array}$ \\
\hline Pursuing new markets & $\begin{array}{l}\text { - Open new business segments } \\
\text { - Maintain a competitive edge in the industry by embracing innovation } \\
\text { - Trigger new opportunity for business monetization } \\
\text { - Value and exploit data generated by the traditional lines of business }\end{array}$ \\
\hline $\begin{array}{l}\text { Making smart data out of big data } \\
\text { for the entire processing chain } \\
\text { (machine-objects and machine-- } \\
\text { environment interactions) }\end{array}$ & $\begin{array}{l}\text { - Process huge volume of complex data efficiently } \\
\text { - Potential for generating added value along the entire value chain } \\
\text { - Improve safety by fostering data fusion } \\
\text { - Acquire useful and unbiased data from various sources of perception } \\
\text { (physical and digital sensors) }\end{array}$ \\
\hline
\end{tabular}




\section{HOW AI SYSTEMS CAN CREATE BUSINESS VALUE}

As indicated in the previous paragraphs, AI systems aiming to provide cognitive insights allow the company to collect smart data that can be used, for example, to better profile segments or adapt the marketing strategy to the specific needs. Automating tasks in manufacturing and production, but also in distribution and logistics, procurement, legal, and R\&D, allow workers to be freed up to be more creative and optimize processes.

The adoption of AI systems (and their underlying AI functions) imposes on companies the need to reengineer a value chain simultaneously with the engineering of the products/services and processes to provide value (Brandenburger and Stuart 1996; Pagani 2013). In this respect, we build on the "three-dimensional concurrent engineering" framework (Fine et al. 2002), which adds value chain engineering to augment the traditional two-dimensional concurrent engineering of products and processes (Fleischer and Liker 1997; Nevins and Whitney 1989; Ulrich and Eppinger 1994).

Adopting this framework, we identify three main ways in which AI systems create value:

1. Product Design: by becoming part of the products themselves;

2. Process Design: by improving performance across the value chain;

3. Supply Chain Design: enabling ecosystems and collaboration with new markets.

\subsection{Value in Product Design: Becoming Part of Products Themselves}

AI allows minimal artifacts to be technologically enriched, adding new potential functions and value layers. In this way, thanks to the digital transformation, analog properties are blended with digital immateriality. This results in objects with invisible technology and essential aesthetics, which are augmented with unexpected properties (Krippendorff 1989). Equipped with sensors, actuators, and information technology, smart (and hence physical) products are at the center of the transformation in business-to-consumer and business-to-business markets (Pardo et al. 2020). They receive information from the physical world (users, the environment, and potentially other objects) through sensors, and act accordingly, modifying their aesthetics and function. This is the case of smart business products (Daley 2017) as opposed to smart consumer products (such as smart meters used in people's homes, connected fridges, or smart speakers such as Amazon Echo, Google Home, or HomePod by Apple). As products 
and services have increasingly embedded digital and AI technologies (i.e., augmented reality, Radio Frequency Identification (RFID) or Quick Response (QR) code, NLP interfaces, deep learning algorithms for image processing), it is becoming more difficult to disentangle business processes from their underlying IT infrastructures (El Sawy 2003). In this perspective, the presence of AI embedded in products adds new value layers or generates new products.

\subsection{Value in Process Design: Improving Performance Across the Value Chain}

AI allows machines to learn from experience, adapt to new inputs, and perform human-like tasks. This is also the principle behind the ethical awareness of the human-centric AI system (described above), which brings safety/ethical checks in the process to optimize the decision-making process leading to the action of the system.

In every business process, $\mathrm{AI}$ works by combining large amounts of data with fast, iterative processing and intelligent algorithms, allowing the software to learn automatically by recognizing patterns in the data. This allows performance to be increased along the value chain.

If we consider the case of healthcare, $\mathrm{AI}$ allows patient care and process efficiencies to be improved. In this case, an effective process design can result in improved care management, remote monitoring, and utilization management. Thanks to AI-assisted image recognition for the detection of malignant traces of cancer, an alert and notification system can automatically go into a final review by the domain expert. Another example is the logistics and transportation industry where the use of machine learning and predictive analytics has already transformed supply chain management, making it a seamless process. Many warehouses use AI-powered robots to sort and package products. Furthermore, AI algorithms are also increasingly being used to find the quickest shipment route.

\subsection{Value in Supply Chain Design: Enabling Ecosystems and Collaboration with New Markets}

The increased connectivity made possible by the adoption of AI systems is also reshaping the structure of industry, allowing the emergence of a much more complex and dynamic ecosystem for growth and innovation (Adner 2006; Iansiti and Levien 2004; Pagani 2013) characterized by an interdependent group of enterprises, people and/or things sharing standardized platforms for a mutually beneficial purpose (such as commercial gain, innovation or common interest). 
In these emerging markets, a platform exists wherever a company brings together two or more distinct groups of actors that need each other in some way, and where the company builds an "infrastructure" (platform) that creates value by reducing distribution, transaction, and "search" costs incurred when these groups interact with one another (Eisenmann et al. 2006). This is the case of Amazon, Alibaba, eBay, and Airbnb, for example.

According to this perspective, a business ecosystem is an orchestrated network where a variety of enterprises that often span multiple sectors come together to work to shared standards around a shared platform to make their products and services compatible. An enterprise could be the organizer of the ecosystem (and the keystone player) or it could be a participant. There are many players/participants in a business ecosystem and they include not only the tight supply chain partners but also many loosely coupled others who are stakeholders contributing to the prosperity and vitality of the business ecosystem (Iansiti and Lakhani 2017).

The implementation of AI systems changes the way industrial companies (i.e., automotive, plane, manufacturing) shape their collaboration within their business ecosystems, enabling cross-boundary industry disruption and thus inducing new forms of business strategies (Burgelman and Grove 2007; Pagani 2013). For example, cars are now connected to digital networks and this connectivity is reshaping the structure of the automotive industry, also influencing a range of connected sectors such as insurance, automotive repairs, and maintenance, road construction, regulation, and infrastructure (Iansiti and Lakhani, 2017). Consequently, theoretical structures for strategy making in nonlinear dynamic environments are also emerging (Pavlou and El Sawy 2010).

\section{COLLABORATION MODES IN HUMAN-CENTRIC AI}

Companies adopting AI systems may benefit from optimizing collaboration between humans and AI but to achieve this goal, they need to understand how machines can most effectively augment humans, how machines can enhance what humans do best, and how to redesign business processes to support this partnership (Wilson and Daugherty 2018). Previous studies (Ransbotham et al. 2017) provide insights on how AI will augment human performance in the workplace. Other studies in this field (Wilson and Daugherty 2018) conclude that human-machine interactions will involve machines providing scale and speed, with humans offering insights and training data.

In order to integrate the ethical dimension of a human-centric AI, we build now on the previous classification of the 867 examples of AI systems applied 
to business processes to further disentangle the level of shared ethical awareness. We distinguish two main dimensions (Figure 1.5):

1. The level of optimization vs creativity/strategy required by the nature of the business activity where the AI system is applied: AI systems may replicate human functions or expand human functions. In this respect, AI is likely to replicate business functions that are repetitive or routine but it has the potential to expand business functions that are more "complex", "creative" or "strategic" (for example artist, scientist, CEO). The "replication of a business function" is done for the purpose of optimization of the tasks to improve the performance of a process already well defined. On the other side, "expanding the function" refers to the possibility to generate new capabilities, thus creating new opportunities.

2. The level of ethical implications: this measures if the machine is autonomous in addressing an ethical decision (unsupervised manner) - "Autonomy", or if it is sharing the decision with humans (supervised manner) - "Collaboration".

Based on the two dimensions identified (Business Function and Level of Ethical Implications), we distinguish four groups of how AI systems may add value layers collaborating with humans (Pagani and Champion 2020) (Figure $1.5)$ :

1. Rote tasks with limited ethical implications: for this first group of AI systems the ethical autonomy is low. AI allows humans to complete repetitive rote tasks and automate a wide variety of business processes but does not produce innovation per se. This is the case of algorithms that automatically recommend movies and songs, place advertisements and detect fraud but also traditional industrial robots with big robotic arms, such as the one in place today in most automotive factories, or machines to optimize manufacturing (big robots operating behind fences to replace humans for full automation); logistics optimization with warehouses' robotics management; or maintenance with drones and mobile platforms; Dirty, Dull \& Dangerous tasks (DDD tasks) performed safely by robots. All these AI systems are used for simple and mechanical tasks. The role of the humans is to supervise AI taking ethical decisions and the machine allows the business function to be replicated and optimized.

2. Simple tasks that require ethical decision-making: when AI systems have autonomous and unsupervised ethical awareness and replace humans in routine and repetitive tasks that require a high level of compassion/ empathy, human support is particularly important. This would be the case of self-aware computer programs that can engage in common-sense reasoning, attain knowledge in multiple domains, and express and understand 
emotions. No such system exists yet that is fully self-aware, but for this type of AI system, the possible risk is getting the human out of the loop in the underlying market domains. Some examples in this area are also robots in hotels, or robots that help disabled people with the mechanics of eating (such as Kinova's robotic arm), support elders or people with disabilities with standing or walking (such as exoskeleton products from Ekso Bionics or ReWalk), or manage medication and provide cognitive stimulation (such as Nao for Autism or Paro for Alzheimer's); it is vital that humans provide the ethical and empathetic components that a robot alone cannot offer. The same risk exists for a vocal chatbot in education or when breaking the social link with service robots in social interactions for elderly care. In all these cases humans have to provide the ethical and empathetic components that AI systems alone cannot provide.

3. Creative tasks with limited ethical components: when AI systems are applied to tasks with a higher level of creativity and complexity still requiring a low level of ethical awareness, we may see that they augment humans offering them new collaborative tools to better accomplish the tasks. This is the case of AI systems applied in finance dealing with the prediction of market assets, or again AI systems in human resources for optimization (CVs classification) or surgical robots. AI systems may also play very significant roles in creative activities such as music, architecture, fine arts, and science, opening up a subfield of AI called Computational Creativity or the study of building software that exhibits behavior that would be deemed creative in humans. Such creative software can be used for autonomous creative tasks, such as inventing mathematical theories, writing poems, painting pictures, and composing music. In these cases, software acts as a creative collaborator rather than a mere tool augmenting human capabilities.

4. Tasks with both creative and ethical components: AI systems applied to tasks with a high level of complexity and creativity and the potential of having a fully autonomous ethical awareness that are not only doing things better than humans but are also capable of taking ethical decisions. This would be the case of an autonomous car (like Tesla or Google's self-driving car projects) that needs to execute complicated, creative tasks while automating high-stakes ethical decisions, such as how to prioritize conflicting safety concerns. Similarly, search and rescue robots used to find and evacuate people from natural disaster sites must leverage both creative and ethical capabilities to perform their tasks safely. While we have made major strides in developing automated tools that can execute complex, ethically charged tasks, it is vital to ensure that human employees leverage both their creative and ethical capabilities to support these systems. 


\begin{tabular}{|c|c|c|}
\hline & Routine tasks & Creative tasks \\
\hline $\begin{array}{l}\text { Limited } \\
\text { ethical } \\
\text { implications }\end{array}$ & $\begin{array}{l}\text { Rote tasks with limited ethical } \\
\text { implications. } \\
\text { Examples: Robotic arms, AGVs, } \\
\text { autonomous forklifts. }\end{array}$ & $\begin{array}{l}\text { Creative tasks with limited } \\
\text { ethical implications. } \\
\text { Examples: Financial tools, } \\
\text { surgical robots. }\end{array}$ \\
\hline $\begin{array}{l}\text { Significant } \\
\text { ethical } \\
\text { implications }\end{array}$ & $\begin{array}{l}\text { Tasks that are relatively simple } \\
\text { but require ethical decision- } \\
\text { making. } \\
\text { Examples: Robots that help } \\
\text { disabled people or elders. }\end{array}$ & $\begin{array}{l}\text { Tasks that require both } \\
\text { creativity and ethical } \\
\text { decision-making. } \\
\text { Examples: Autonomous } \\
\text { vehicles, search and rescue } \\
\text { robots. }\end{array}$ \\
\hline
\end{tabular}

Source: Pagani and Champion (2020).

\section{Figure 1.5 Four types of AI supported tasks}

\section{CONCLUSIONS}

Based on the evidence presented in this chapter we may argue that human-centric AI brings value to business processes, may transform products and shape business ecosystems. The future success of business endeavors doesn't depend on AI systems, but on managers capable of leveraging digital technologies to enhance human potential, putting the human at the center of the loop. AI systems are conceived to help humans and collaborate with them. Human-centric AI brings the human and ethics to the center of these systems. According to the type of business process impacted, the collaboration between humans and AI systems may share a different level of shared ethical awareness and replicate or expand business functions.

\section{NOTES}

1. A feedback loop is the part of a system in which some portion of the system's output is used as input for future operations. See Ashby (1956).

2. See video AI, Ain't I a Woman? from Joy Buolamwini on the gender discrimination due to biased data sets. Retrieved from: https://www.youtube.com/watch?v= QxuyfWoVV98.

3. The journalist Judith Duportail revealed in 2019 the gender biases in the algorithms developed by Tinder (Duportail 2019). 
4. As specified by the European Union harmonization legislation, the letters $C E$ appear on many products traded on the extended Single Market in the European Economic Area (EEA). They signify that products sold in the EEA have been assessed to meet high safety, health, and environmental protection requirements.

5. See https://ethicsinaction.ieee.org/\#set-the-standard.

6. Problem formalized by Philippa Foot: "suppose that the driver of a runaway tram can only steer from one narrow track on to another; five men are working on one track and one man on the other; anyone on the track he enters is bound to be killed"; what is the right thing to do? (Foot 1978).

\section{REFERENCES}

Adner, R. (2006). Match your innovation strategy to your innovation ecosystem, Harvard Business Review, 84(4), 98-107.

Ashby, W.R. (1956). An Introduction to Cybernetics, London: Chapman \& Hall.

Balagué, C. and Rochd, E.M. (2020). Towards using responsible artificial intelligence in product recommender systems in marketing. Retrieved from: https://hal.archives -ouvertes.fr/hal-02332033.

Brandenburger, A.M. and Stuart, H.W. (1996). Value-based business strategy, Journal of Economics \& Management Strategy, 5(1), 5-24.

Burgelman, R.A. and Grove, A.S. (2007). Let chaos reign, then rein in chaosrepeatedly: Managing strategic dynamics for corporate longevity, Strategic Management Journal, 10(28), 965-79.

Daley, J. (2017). Insecure software is eating the world: Promoting cybersecurity in an age of ubiquitous software-embedded systems, Stanford Technology Law Review, 19(3), 533-46.

Davenport, T.H. (2018). The AI Advantage: How to Put the Artificial Intelligence Revolution to Work. Cambridge, MA: MIT Press.

Davenport, T.H. and Ronanki, R. (2018). Artificial intelligence for the real world, Harvard Business Review, 96(1), 108-16.

Dawar, N. and Bendle, N. (2018). Marketing in the digital age of Alexa, Harvard Business Review, 96(3), 80-86.

DeepIndex (2020). Keeping Track of What AI Can Do and Where it Is Being Applied. DeepIndex Report.

Duportail, J. (2019). L'Amour Sous Algorithme. Paris: Editions de la Goutte d'Or.

Eisenmann, T., Parker, G. and Van Alstyne, M.W. (2006). Strategies for two-sided markets, Harvard Business Review, 84(10), 92-101.

El Sawy, O.A. (2003). The IS Core IX: The 3 faces of IS identity: Connection, immersion, and infusion, Communications of the AIS, 12(39), 588-98.

European Commission (2019). High-level expert group on Artificial Intelligence, Ethics Guidelines for Trustworthy AI, European Commission.

European Commission (2000). Charter of fundamental rights of the European Union, Official Journal of the European Communities, 364(1), 1-21.

Fine, C.H., Vardan, R., Pethick, R. and El Hout, J. (2002). Rapid-response capability in value chain design, MIT Sloan Management Review, 43(2), 69-75 (Winter).

Fleischer, M. and Liker, J.K. (1997). Concurrent Engineering Effectiveness. Cincinnati, $\mathrm{OH}$ : Hanser Gardner Publications. 
Foot, P. (1978). The problem of abortion and the doctrine of the double effect. In P. Foot (ed.), Virtues and Vices and Other Essays in Moral Philosophy. Oxford: Oxford University Press, pp. 19-32.

Iansiti, M. and Lakhani, K.R. (2017). The truth about Blockchain, Harvard Business Review, January-February, pp.118-127. Retrieved from: https://hbr.org/2017/01/the -truth-about-blockchain.

Iansiti, M. and Levien, R. (2004). The Keystone Advantage: What the New Dynamics of Business Ecosystems Mean for Strategy, Innovation, and Sustainability. Boston, MA: Harvard Business School Press.

Musikanski, L., Havens, J., \& Gunsch, G. (2018). IEEE. P7010 Well-being Metrics Standard for Autonomous and Intelligence Systems ${ }^{\mathrm{TM}}$ : An introduction. IEEE Standards.

Kirchmer, M. (2017). High Performance through Business Process Management: Strategy Execution in a Digital World. Cham: Springer.

Krippendorff, K. (1989). Content analysis. In E. Barnouw, G. Gerbner, W. Schramm, T.L. Worth and L. Gross (eds), International Encyclopedia of Communication, Vol. 1. New York, NY: Oxford University Press, pp. 403-407.

McCarthy, J., Minsky, M.L., Rochester, N. and Shannon, C.E. (2006). A proposal for the Dartmouth Summer Research Project on Artificial Intelligence, August 31, 1955, AI Magazine, 27(4), 12-14.

Nevins, J.L. and Whitney, D.E. (1989). Concurrent Design of Products and Processes: A Strategy for the Next Generation in Manufacturing. New York, NY: McGraw-Hill.

Pagani, M. (2013). Digital business strategy and value creation: Framing the dynamic cycle of control points, MIS Quarterly, 37(2), 617-32.

Pagani, M. and Champion, R. (2020). Making sense of the AI landscape, Harvard Business Review, 17 November. Retrieved from: https://hbr.org/2020/11/making -sense-of-the-ai-landscape.

Pardo, C., Yvens, B.S. and Pagani, M. (2020). Are products striking back? The rise of smart products in business markets, Industrial Marketing Management, 90, 205-20.

Pavlou, P.A. and El Sawy, O.A. (2010). The 'third hand': IT enabled competitive advantage in turbulence through improvisational capabilities, Information Systems Research, 21(3), 443-71.

Ransbotham, S., Kiron, D., Gerbert, P. and Reeves, M. (2017). Reshaping business with artificial intelligence: Closing the gap between ambition and action, MIT Sloan Management Review, 59(1), Research Report.

Schonberger, R. (1990). Building a Chain of Customers: Linking Business Function to Create a World-class Company. New York, NY: The Free Press.

Ulrich, K.T. and Eppinger, S.D. (1994). Product Design and Development. New York, NY: McGraw-Hill.

United Nations SDG (2015). Take action for the Sustainable Development Goals. Retrieved from: https://www.youtube.com/watch?v=QxuyfWoVV98.

Weske, M. (2012). Business Process Management: Concepts Languages, Architectures, 2nd edn. Berlin: Springer.

Wilson, H.J. and Daugherty, P.R. (2018).Collaborative intelligence: Humans and AI are joining forces, Harvard Business Review, July-August, 1 July. Retrieved from https://hbr.org/2018/07/collaborative-intelligence-humans-and-ai-are-joining -forces. 